\title{
Cerebral Venous Sinus Thrombosis as a Presentation of COVID-19
}

\author{
Christopher Hughes, Tom Nichols, Martin Pike, Christian Subbe, Salah Elghenzai \\ Betsi Cadwaladr University Health Board, Bangor, Wales, UK
}

Doi: 10.12890/2020_001691 - European Journal of Case Reports in Internal Medicine - C EFIM 2020

Received: $26 / 04 / 2020$

Accepted: $27 / 04 / 2020$

Published: $29 / 04 / 2020$

How to cite this article: Hughes C, Nichols T, Pike M, Subbe C, Elghenzai S. Cerebral venous sinus thrombosis as a presentation of COVID-19. EJCRIM 2020;7: doi:10.12890/2020_001691.

Conflicts of Interests: The Authors declare that there are no competing interests.

Acknowledgements: Christopher Hughes and Tom Nichols contributed equally to the manuscript.

This article is licensed under a Commons Attribution Non-Commercial 4.0 License

\section{ABSTRACT}

Coronavirus disease 19 (COVID-19) is caused by severe acute respiratory syndrome coronavirus 2 (SARS-CoV-2). We describe the case of a 59-year-old man who presented with headache, hypertension and a single episode of fever with no other symptoms. He subsequently developed unilateral weakness. Computer tomography identified a cerebral venous sinus thrombosis (CVST). A subsequent test for COVID-19 was positive. This is the first report of CVST as a presenting symptom of COVID-19 infection.

\section{LEARNING POINTS}

- Thrombotic events may be the initial presenting symptom of COVID-19.

- These thrombotic events include stroke, venous thromboembolism, pulmonary embolism and cardiac complications.

- Clinicians should carefully consider the risk of thrombosis in patients positive for COVID-19, including prophylaxis and treatment beyond discharge.

\section{KEYWORDS}

COVID-19, cerebral venous sinus thrombosis, anticoagulation, stroke

\section{INTRODUCTION}

Coronavirus disease 19 (COVID-19) is caused by severe acute respiratory syndrome coronavirus 2 (SARS-CoV-2). It first appeared in December 2019 in Wuhan, China. The World Health Organization declared a pandemic in March 2020. COVID-19 is primarily a disease with respiratory manifestations ${ }^{[1]}$, but there are increasing reports of cardiovascular ${ }^{[2,3]}$ and thromboembolic complications ${ }^{[4-8]}$. These are partially attributed to systemic inflammation and coagulopathy in patients with COVID-19 infection. We report the first case of cerebral venous sinus thrombosis (CVST) as a presenting symptom of COVID-19 infection.

\section{CASE DESCRIPTION}

A 59-year-old man was referred to our emergency department by an out-of-hours general practitioner. The patient reported a 4-day history of a constant right-sided fronto-temporal headache, with gradual onset and increasing severity. He was a life-long non-smoker with a past medical history of non-insulin-dependent diabetes and hypertension. He weighed $148 \mathrm{~kg}$. On admission, he presented with no neurological deficits and no respiratory signs or symptoms. He had persistent severe headache and one episode of fever with a blood pressure of $170 / 111 \mathrm{mmHg}$, oxygen saturations of $99 \%$ on room air and a respiratory rate of 20 breaths per minute. Chest radiography showed bilateral infiltrates, and so a nasopharyngeal Covid-19 swab was taken which confirmed active COVID-19 infection. Laboratory findings are reported in Table 1.

CT of the head showed hyperdensity within the superior sagittal sinus, right transverse sinus, sigmoid sinus and upper right internal jugular vein suggestive of venous thrombosis. A CT venogram was reported as normal. The patient's symptoms improved, and he was discharged. 
However, he re-presented 4 days later with acute neurological symptoms with examination showing reduced power and numbness in the right upper and lower limbs, slurred speech and expressive dysphasia. He had a National Institutes of Health Stroke Scale (NIHSS) score of 10. The CT venogram was re-reviewed and a filling defect in the right sigmoid and transverse sinus involving the torcula was correctly identified (Figs. 1 and 2). The patient was treated with low molecular weight heparin (LMWH). After 24 hours, the NIHSS score improved to 4. The patient was deemed suitable for discharge and commenced on apixaban $10 \mathrm{mg}$ twice a day for 7 days with review by the local thrombosis service. At the time of writing the patient is recovering at home.
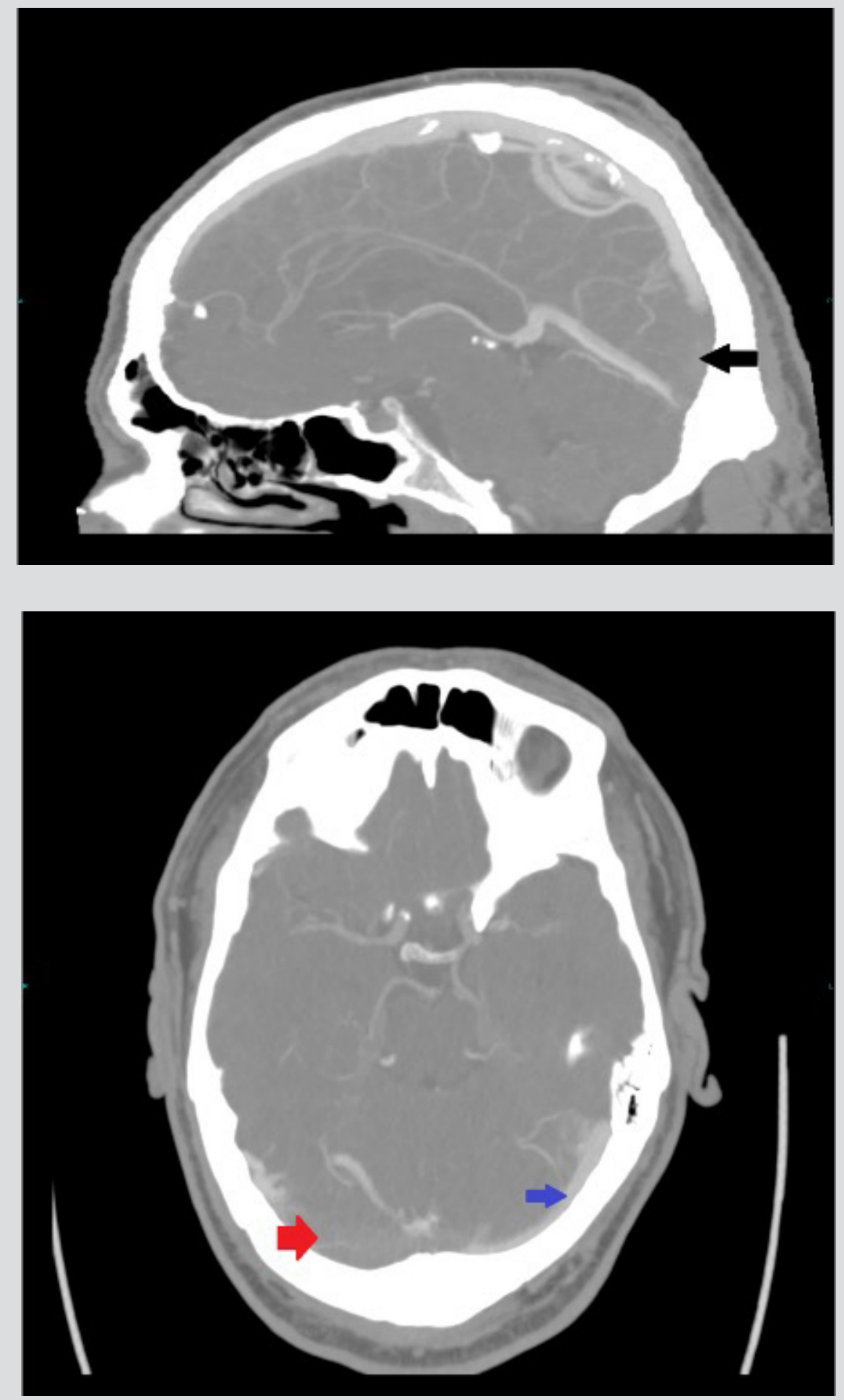

Figure 1. CT venogram (sagittal reconstruction - $4 \mathrm{~mm}$ maximum intensity projection). Contrast in the sagittal sinus should extend inferiorly to meet the straight sinus at the torcula/confluence of the sinuses. In this image, the thrombus fills the lower part of the sagittal sinus, making it similar in density to the brain (black arrow). Note that the sinuses are irregular and variable, and a similar appearance would be seen if part of the sinus were out of the plane of the image

Figure 2. CT venogram (4 mm MIP axial image, bone windows). The dominant sinus is the right one - asymmetry of the sinuses is normal. Contrast is seen in the smaller left sinus (blue arrow), but not where the thrombus fills most of the right transverse sinus (red arrow) 


\begin{tabular}{|c|c|c|}
\hline Sample type and normal range & At admission & Day 5 \\
\hline WBC (4-11×10\%/I) & 7.6 & 6.3 \\
\hline $\mathrm{Hb}(130-180 \mathrm{~g} / \mathrm{l})$ & 165 & 157 \\
\hline Platelets $\left(150-400 \times 10^{9} / \mathrm{I}\right)$ & 202 & 234 \\
\hline Neutrophils $\left(1.7-7.5 \times 10^{9} / \mathrm{I}\right)$ & 5.7 & 4.0 \\
\hline Lymphocytes $\left(1.0-4.5 \times 10^{9} / \mathrm{I}\right)$ & 1.2 & 1.5 \\
\hline PT $(9.0-12.0 \mathrm{sec})$ & 11.1 & 11.2 \\
\hline APTT $(23.0-33.0 \mathrm{sec})$ & 22.3 & 19.7 \\
\hline Fibrinogen $(2.0-4.0 \mathrm{~g} / \mathrm{l})$ & 3.9 & 4.9 \\
\hline $\mathrm{CRP}(<5 \mathrm{mg} / \mathrm{l})$ & 15 & 20 \\
\hline Creatinine $(58-110 \mu \mathrm{mol} / \mathrm{l})$ & 57 & 60 \\
\hline Urea $(2.5-7.8 \mathrm{mmol} / \mathrm{l})$ & 4.3 & 4.5 \\
\hline $\operatorname{ESR}(0-15 \mathrm{~mm} / \mathrm{h})$ & ND & 31 \\
\hline
\end{tabular}

Table 1. Pathology results on day of admission and on day 5 The tests demonstrate a mild inflammatory response and no signs of bio-chemical dehydration. Abnormal values are shown in red. APTT, activated partial thromboplastin time; ESR, erythrocyte sedimentation rate; Fibrinogen, Clauss fibrinogen level; $\mathrm{Hb}$, haemoglobin; ND, not done; PT, prothrombin time; WBC, white blood cell count

\section{DISCUSSION}

As of the 26 April 2020 there were over 2.9 million cases of COVID-19 worldwide and more than 200,000 deaths ${ }^{[9]}$. It is an emerging disease and knowledge within the scientific and clinical community is increasing, but gaps remain in the collective understanding. While COVID-19 is primarily a disease with respiratory manifestations ${ }^{[1]}$, there are increasing reports of cardiovascular and thrombotic complications which are important for clinicians to be aware of. It is known that during infection with COVID-19 there is a pro-inflammatory immune response, that the severity of inflammation corresponds with the severity of the clinical situation, and that high levels of inflammatory processes are associated with a hypercoagulable state. Coagulopathy has been observed in similar diseases [10] including severe acute respiratory syndrome (SARS) and Middle East respiratory syndrome (MERS), caused by the SARS-CoV and MERS-CoV coronaviruses, respectively ${ }^{[11]}$. Expert consensus suggests prophylactic treatment with LMWH should be considered during admission and for 7-14 days after discharge for patients with COVID-19. Clinicians need to consider the options for treatment doses during admission and beyond discharge in patients with multiple risk factors ${ }^{[4-8]}$.

CVTS accounts for only $0.5-1 \%$ of strokes. It can present with a wide range of clinical spectra predominantly affecting younger patients, with a female to male ratio of $3: 1$, indicating a significant female preference ${ }^{[12]}$. There are inherited and acquired risk factors for CVTS. In this case, inherited causes were thought unlikely due to age and a lack of prior thrombotic events. Acquired causes include brain tumours, head trauma and local central nervous system infection, none of which were present in this patient. A prothrombotic state is a risk factor for CVTS and this patient was positive for COVID-19. With the emerging evidence of thrombotic complications and prothrombotic states in COVID-19, we conclude COVID-19 was the risk factor precipitating this episode of CVTS. 


\section{REFERENCES}

1. Huang C, Wang Y, Li X, Ren L, Zhao J, Hu Y, et al. Clinical features of patients infected with 2019 novel coronavirus in Wuhan, China. Lancet 2020;395(10223):497-506.

2. Long B, Brady WJ, Koyfman A, Gottlieb M. Cardiovascular complications in COVID-19. Am J Emerg Med 2020 Apr 18. pii: S0735-6757(20)30277-1. doi: 10.1016/j. ajem.2020.04.048 [Epub ahead of print].

3. Kochi AN, Tagliari AP, Forleo GB, Fassini GM, Tondo C. Cardiac and arrhythmic complications in patients with COVID-19. J Cardiovasc Electrophysiol 2020 Apr 9. doi: 10.1111/ jce.14479 [Epub ahead of print].

4. Marietta M, Ageno W, Artoni A, De Candia E, Gresele P, Marchetti M, et al. COVID-19 and haemostasis: a position paper from Italian Society on Thrombosis and Haemostasis (SISET). Blood Transfus 2020 Apr 8. doi: 10.2450/2020.0083-20 [Epub ahead of print].

5. Bikdeli B, Madhavan MV, Jimenez D, Chuich T, Dreyfus I, Driggin E, et al. COVID-19 and thrombotic or thromboembolic disease: implications for prevention, antithrombotic therapy, and follow-up. J Am Coll Cardiol 2020 Apr 15. pii: S0735-1097(20)35008-7. doi: 10.1016/j.jacc.2020.04.031 [Epub ahead of print].

6. Song JC, Wang G, Zhang W, Zhang Y, Li WQ, Zhou Z, et al. Chinese expert consensus on diagnosis and treatment of coagulation dysfunction in COVID-19. Mil Med Res 2020;7(1):19.

7. Zhai Z, Li C, Chen Y, Gerotziafas G, Zhang Z, Wan J, et al. Prevention and treatment of venous thromboembolism associated with coronavirus disease 2019 infection: a consensus statement before guidelines. Thromb Haemost 2020 Apr 21. doi: 10.1055/s-0040-1710019 [Epub ahead of print].

8. Casini A, Alberio L, Angelillo-Scherrer A, Fontana P, Gerber B, Graf L, et al. Thromboprophylaxis and laboratory monitoring for in-hospital patients with COVID-19 - a Swiss consensus statement by the Working Party Hemostasis. Swiss Med Wkly 2020;150:w20247.

9. John Hopkins University. COVID-19 Case Tracker 2020. Available from: https://coronavirus.jhu.edu (accessed 28 April 2020).

10. Magdi M, Rahil A. Severe immune thrombocytopenia complicated by intracerebral haemorrhage associated with coronavirus infection: a case report and literature review. Eur J Case Rep Intern Med 2019;6(7):001155

11. Giannis D, Ziogas IA, Gianni P. Coagulation disorders in coronavirus infected patients: COVID-19, SARS-CoV-1, MERS-CoV and lessons from the past. J Clin Virol 2020;127:104362.

12. Alvis-Miranda HR, Milena Castellar-Leones S, Alcala-Cerra G, Rafael Moscote-Salazar L. Cerebral sinus venous thrombosis. J Neurosci Rural Pract 2013;4(4):427-438. 